\title{
Örnek Olay Üzerinden Mantıksal ve Eleştirel Bakış Açısı
}

\author{
DOI: $10.26466 /$ opus. 872707
}

*

\author{
Dilek Bașerer * \\ * Arş. Gör. Dr., Atatürk Üniversitesi, Kazım Karabekir Eğitim Fakültesi, Felsefe Grubu Eğitimi \\ E-Posta: dilek.baserer@atauni.edu.tr \\ ORCID: 0000-0001-7098-3645

\section{Öz}

Doğru düşünmenin aracı olarak mantık, aynı zamanda tutarlı düşünme, sistemli düşünme ve eleştirel düşünmeyi de beraberinde getirmektedir. Mantık kural ve ilkelerine uygun düşünme türü olan mantıksal düşünme bu noktada ortaya çıkmaktadır. Mantıksal düşünme, çeşitli akıl yürütme ilke ve kurallar ile doğru kararlar vermede, bir problem ile karşılaşıldığında o probleme eleştirel ve akılcr yaklaşmada etkili olmaktadır. Bu nedenle de yapılan çalışma ile mantıksal muhakeme gücünü kullanılırken hangi yolların izlenmesi gerektiği ele alınmıştır. Bununla birlikte izlenen yolda eleştirel bakış açısının hangi noktada ortaya çıktığına da değinilmiştir. Böylece mantıksal akıl yürütmenin eleştirel bakış açısıyla değerlendirilmesini gösteren örnek olay ile ele alınmast ile çalışmanın amacı ve önemi ortaya konulmaya çalışılmıştır. Çalışmada yöntem olarak nitel araştırma yöntemi olarak literatür taraması yapılmıştır. Veriler mantıksal ve eleştirel düşünme ile ilgili çeşitli makale ve kitaplardan yararlanılarak toplanmış ve yorumlama ile analiz edilmiştir. Çalışma soncunda örnek olay ve örneklerden hareketle mantıksal ve eleştirel düşünme için bir probleme karşı nasıl yaklaşılması gerektiğine değinilmiştir. Özellikle bir olayla karşı karşıya kalındığında artı ve eksi yanlarının hepsinin değerlendirilmesi, düşünmeden acele karar verilmemesi, alternatif yollarm ve uzman desteğinin es geçilmemesi ve yeterli kant elde edilene kadar sonuç çıkarmamak gerektiği sonucuna ulaşılmıştır.

Anahtar Kelimeler: Mantık, mantıksal düşünme, akıl yürütme, eleştirel düşünme 


\title{
Logical and Critical Perspective on Case Study
}

\begin{abstract}
Logic, as a tool for correct thinking, also brings along consistent thinking, systematic thinking, and critical thinking. Logical thinking, a type of thinking in accordance with logic rules and principles, emerges at this point. Logical thinking is effective in making correct decisions with various reasoning principles and rules, and in approaching a problem critically and rationally when it is encountered. For this reason, the methods to follow when using logical reasoning power are discussed with the study. However, it was also mentioned at what point the critical perspective emerged on the path followed. Thus, the aim and importance of the study was tried to be revealed by addressing the logical reasoning with a case study showing the evaluation of it from a critical perspective. As a method in the study, a literature review was made as a qualitative research method. The data were collected from various articles and books on logical and critical thinking and analyzed with interpretation. At the end of the study, it is mentioned how to approach a problem for logical and critical thinking based on case studies and examples. It was concluded that especially when faced with an incident, all of its pros and cons should be evaluated, not to make hasty decisions without thinking, alternative ways and expert support should not be omitted, and conclusions should not be drawn until sufficient evidence is obtained.
\end{abstract}

Keywords: Logic, logical thinking, reasoning, critical thinking 


\section{Giriş}

\section{Mantıksal Düşünme}

Aklın bağımsız ve kendine özgü eylemi olan düşünme; bağlantıları ve biçimleri kavrama, karşılaştırmalar yapma, ayırma, birleştirme yetisidir. Düşünme; içinde bulunulan durumu anlayabilmek amacıyla yapılan aktif, amaca yönelik, organize zihinsel bir süreçtir (Demirel, 2005). Mantık ise kesin yargılara varmak için araç görevi gören kanıtların incelenmesidir. Doğru düşünme aracı olan mantık, kişilere doğru, tutarlı, sistemli düşünme yollarını göstermektedir. Bu düşünme yollarını da bir düşünme türü olarak mantıksal düşünme ortaya koymaktadır. Mantıksal düşünme, problem çözebilmeyi, kavramsal analizlerde bulunabilmeyi, akıl yürütmeyi gerçekleştiren yolları kullanabilmeyi, soyut yapıları tanıyabilmeyi, iki durum arasındaki ilişkiyi ayırt edebilmeyi ve çeşitli kıyas ve çıkarımlar yaparak mantıklı kararlar verebilmeyi sağlayan bir düşünme türüdür (Başerer, 2017).

Piaget, mantıksal düşünmeyi somut ve soyut işlemler aşamasında gözlemlenen bir yetenek olarak tanımlar. Somut işlemler aşamasındaki öğrenciler, somut problemlerin çözümünde mantıksal düşünme becerilerini kullanabilirler. Soyut işlemler aşamasında bu öğrenciler mantıksal düşünme açsindan yetişkin düzeyine ulaşırlar (Bozdoğan, 2007). Bu yetenek, bireyin bir problemi zihinsel işlemleri kullanarak çözebilme veya belirli genellemeler veya soyutlamalar yaparak ilke ve kurallara ulaşma yeteneğini ifade eder (Korkmaz, 2002). Bu şekilde görüldügünde, mantıksal düşünme yetenekleri doğru ve tutarlı olarak gelişmiş davranış gerektirir.

Mantıksal düşünme süreci, bir problemin fikirlerini, gerçeklerini ve sonuçlarını elde etmek ve bunları ardışık bir sıraya koymak demektir. Mantıksal düşünme, çocuğun "bilmiyorum, bu çok zor" demesini engeller. Bu yetenek, çocuğun daha iyi kavramasına ve daha derinlemesine düşünerek çözüme tek başına ulaşmasına olanak sağlar (Cıbık, 2006).

\section{Eleștirel Düşünme}

Eleştirel düşünme, bilginin daha iyi öğrenilmesi, yeni durumlara uygulanması ve değerlendirme yeteneğinin geliştirilmesidir. Kendi düşünce sürecimizin bilincinde olarak, başkalarının düşünce süreçlerini göz önünde tutarak, öğrendiklerimizi uygulayarak kendimizi ve çevremizde yer alan olayları 
anlayabilmeyi amaç edinen aktif ve düzenli zihinsel süreçtir (Semerci, 2003; Cüceloğlu, 2003). Aynı zamanda eleştirel düşünme, kendi düşüncelerimizi ve başkalarının fikirlerini anlayabilmek ve düşünceleri açıklayabilme becerimizi geliştirmek için etkin, örgütlü ve işlevsel bir bilişsel süreçtir. Bir problem durumunu bilimsel, kültürel ve sosyal standart ölçütlere göre, tutarlılık ve geçerlilik bakımlarından yargılama ve değerlendirmede ise koşulan tavır, bilgi ve süreçlerin bütünüdür (Kazancı, 1989; Zayif, 2008).

Eleştirel düşünme, kendi düşünmemizi ve başkalarının düşünmelerini dikkatlice inceleyerek dünyamızı yorumlamak için gösterdiğimiz aktif, amaçlı ve örgütlü çabalarımızdır. İnsanın neye inanacağına ya da neye karar vereceğine odaklanan, mantıklı ve dikkatli düşünme olan eleştirel düşünme, özel bir düşünce alanına ya da biçimine ilişkin kusursuz düşünceyi ortaya çıkaran disiplinli ve öz denetimli düşünce biçimidir. (Şahinel,2002; Koç, 2011).

Bütün bu tanımlardan yola çıkarak eleştirel düşünmenin; bireyin problem çözme, karar verme gibi düşünme süreçleri ile sahip olduğu düşünme becerilerinin farkında olması ve bu zihinsel süreci etkin olarak gerçekleştirmesi seklinde genel bir tanım yapılabilir. Aynı zamanda mantıksal akıl yürütmeyi içermesi ile eleştirel düşünme, doğru kararlar verme konusunda mantıksal düşünme ile bağlantılı olan bir düşünmedir.

\section{Çalışmanın Amacı ve Önemi}

Bu çalışmanın amacı mantıksal akıl yürütme becerilerini geliştirirken eleştirel bakış açısı ile bu becerileri ortaya çıarmaktır. Mantıksal muhakeme becerileri, birinin fikrini anlamada, amaçlar için nedenler üretmede, başkaları tarafından verilen nedenleri değerlendirmede, neyi yapıp yapmamaya karar vermede, hangi bilgileri kabul veya reddedileceğine karar vermede etkilidir. Eleştirel düşünme becerisi ise, yargılarda bulunma becerisidir. Bu beceriler göz açıp kapayıncaya kadar ortaya çıkan ani yargılar değil, dikkatli muhakeme gerektirenlerdir. Bu nedenle de mantıksal düşünme ile bağlantılıdır.

Nitelikli muhakeme, mantıksal akıl yürütme veya eleştirel düşünme olarak adlandırılabilir. Mantıksal akıl yürütme, öğrenilebilen ve geliştirilebilen bir beceridir. Mantıksal muhakemenin zıttı eleştirel olmayan düşünmedir. $\mathrm{Bu}$ nedenle de çalışmada mantıksal akıl yürütmeye paralel olarak eleştirel bakışa da yer verilmiştir. Bu çalışmada amaç, mantıklı olmanın, mantıksal olarak 
akıl yürütmenin ne anlama geldiğini açılanmak ve örnek olay ve örnekler üzerinden eleştirel düşünme ile ilişkisine değinmektir. Çalışma aynı zamanda kişinin kendi hayatı hakkında daha etkili kararlar vermenin bir yolu olarak mantıksal muhakemenin yararlılığını göstermekte ve kişinin neye inanacağı ve ne yapacağ ile ilgili eleştirel olarak kararlar verme konusunda fikir sunmaktadır. Çalışma, cümlelerdeki tutarsızlığı görmek, önermelerdeki netliği, eksikliği, sorunları, yanılgiları tespit etmek ve önlemek (muhakeme hataları) ile kanıtlarla açıklamalar üretmek ve geliştirmek adına önem taşımaktadir.

\section{Yöntem}

Örnek olaylardan hareketle bir olay karşısında mantıksal ve eleştirel olarak nasıl bakılacağını göstermeye ve yorumlamaya dair bir çalışma olduğundan yöntem, literatür taraması ile oluşturulmuştur. Literatür taraması, belirli bir konuda yayınlanmış araştırma sonuçları ve kuramsal yazınların sistemli bir şekilde aranması, taranması ve yorumlanması olarak tanımlanmaktadır (Cooper, 1989; Bruce, 1994; Caspers, 1998; Afolabi, 1992).

\section{Veri Toplama Araçları}

Çalışmanın veri toplama araçlarını, alan yazında yer alan mantıksal düşünme ve eleştirel düşünme ile ilgili olan makale ve kitaplar oluşturmaktadır.

\section{Verilerin Toplanması}

Bu çalışmada alan yazın incelemesi arama, tarama, derleme ve yorumlama olmak üzere dört aşamada gerçekleştirilmiştir.

Arama Süreci: Bu süreçte literatür taraması yapmak amaciyla mantıksal düşünme ve eleştirel düşünme ile ilgili makale ve kitap araştırmaları yapılmıştır.

Tarama Süreci: Arama sonucunda çalışmanın amacına uygun bulunan makale ve kitaplar bir tarama çerçevesi oluşturularak taranmıştır.

Derleme Süreci: Bu aşamada, alınan notlar ile temalara ulaşılmıştır. Makalelerin incelenmesinden ortaya çıkan temalar şu başlıklarda toplanmış ve 
isimlendirilmiştir: mantık, mantıksal düşünme, akıl yürütme, mantıksal muhakeme, eleştirel düşünmedir.

Yorumlama Süreci: Tarama sürecinin tamamlanmasının ardından örnek olay ele alınan temalar çerçevesinde yorumlanmıştır.

\section{Bulgular}

\section{Örnek Olay}

Bu durumu hayal edin. İki arkadaşınız ile ulusal bir vahşi yaşam parkında dört günlük sadece bir sırt çantalı gezintidesiniz. Yaz havası harika, manzara egzotik ve iyi vakit geçiriyorsunuz. Bölgeye ulaşmak için birkaç saat araba sürdünüz ve sonra şu anki kamp yerinize altı saat yürüdünüz. Üçünüz tüm yiyeceklerinizi, suyunuzu, uyku tulumlarınızı ve çadırlarınızı taşıdınız. Dün gece, birinin yanlışlıkla büyük su kabını kırdığını keşfettin. Bu nedenle de yanınızda su bulunmamakta. Yakınlarda bir akarsu olmasına rağmen, normalde bir dereden içmiyorsunuz ve su sterilizasyon tableti paketlerinizin son dakikada evde bıraktığınız diğer ceketinizin cebinde olduğunu hatırladınız. Üçünüz susadınız ve dört elma dışında sadece susuz yiyecekler yanınızda bulunmakta. Bu durumda ne yaparsinız? Bu arada kimse cep telefonu getirmedi. Bağırabilirsin, ama bu pek yardımcı olmaz; yolculuk başladığından beri başka yürüyüşçü görmediniz. Arkadaşlarınızdan biri bir fikri olduğunu söyler. Bu da deredeki suyu kaynatılabilineceğine dair bir fikirdir. Su soğuduktan sonra içip kahvaltı yapıp güzel zaman geçirmeye devam edebilirsiniz. Sonra diğer arkadaşınız park yerinde bir tabela gördüğünden bahseder. Tabela bir uyarı içermektedir. Bu uyarı Giardia adında bir paratizin bölgedeki birçok derede bulunduğu ve sterilizasyon tabletlerinin kalmadığına dair bir uyarıdır. Ayrıca tabeleda Giardia sizi hasta eden bir mikroorganizmadır, şeklinde başka bir uyarı daha bulunmaktadır. Sen ve arkadaşın bunu daha önce hiç duymadınız. Fakat diğer arkadaşın suyu kaynatmanın yaratıkları öldüreceğine bahse girmeye hazır olduğunu söylüyor. "Ayrıca, derimizde Giardia olmayabilir. İlk olarak suyu ben içeceğim der. Ama diğer arkadaşın "Hayır, bunu yapma," diye tepki vermektedir. Nedeni ise bunu içen başka birinde kronik ishal, karın krampları, şişkinlik, yorgunluk ve kilo kaybı gibi semptomların görülmesidir. Ayrıca,"Giardia ile ilgili park levhaları muhte- 
melen organizmalar kaynatılarak öldürülemediği için asılmıştır."diyor. Ancak, işareti yorumladığından emin olmadığını itiraf ediyor, bu yüzden çoğunluğun istediği şeyi yapmaya karar veriyor. Üçünüzün yürüyüş yaparken ve yardımcı olabilecek biriyle, belki Giardia hakkında daha fazla bilgi sahibi olan veya fazladan su sterilizasyon tabletleri olan bir yürüyüşçüyle tanışırken şanslı olabileceğinizi ekliyor. Sonra tekrar, o kadar şanslı olmayabilirsiniz; yolda kimseyi görmediniz. Bu nedenle de ikinci arkadaşın çoğunluğun kararına uymayı kabul ediyor. Kalmak istiyor ama tek başına değil. Yine de ilk arkadaşının nedenlerine ikna olmamış durumda. Bu nedenle "Bakın" diyor, "Eğer dere zehirli olsaydı, içindeki her şey ölü görünürdü. Derede su örümcekleri ve bitkiler var. Bu ölüm tuzağı değil." Bu noktada hayatın küçük kararlarından biriyle karşı karşıyasınız: Bu durum hakkında ne yapıyorsunuz? (Dowden, 2019).

Örnek olay değerlendirildiğinde yapılacak olan şey mantıksal muhakemedir. Çünkü mantıklı bir muhakeme yapmak daha rasyoneldir. Mantıksal muhakemenin ilk adımı genellikle iyi bir tavsiye almaktır. Zaten bir tavsiyeniz var, ancak bunun iyi olup olmadığına nasıl karar verirsiniz? İyi bir tavsiyeyi belirlemenin en iyi yolu iyi nedenlerle yedeklenebilmesidir. Illk arkadaşınızın eve geri dönme tavsiyesi şu nedenlerle desteklenmektedir: Giardia almanın sonuçları oldukça kötüdür ve postalanan işaretler muhtemelen kaynamanın işe yaramayacağını göstermektedir. Maalesef kaynama konusunda emin değil. Yani yük omuzlarınıza düşüyor. O yapmasa bile mantığını yedekleyebilir misin? Ya da mantığının iyi olmadığını gösterebilir misin?

Bir ifadeyi desteklemenin bir yolu, bunu yapan kişinin bir uzman olduğunu belirtmektir. Yani arkadaşlarının kimlik bilgilerini düşünüyorsunuz. Bakalım, ilk arkadaşın psikoloji alanında okuyan bir öğrenci ve ikinci arkadaşın iletişim öğrencisi ve bir evcil hayvan dükkanında çalışıyor. Bu onları Giardia ve içme suyunun güvenliği konusunda yetkili yapar mı? Hayır. Yani bir uzmana ihtiyacınız varsa, başka bir yerde arama yapmanız gerekecektir. Ama kendinize soruyorsunuz, bir uzmandan daha fazla bilgi aramak gerçekten zahmete değer mi? Arama muhtemelen park yerinin yakınındaki korucu istasyonuna geri gitmeyi gerektirecektir. Ayrıca, uzmanın tavsiyesi sterilizasyon tabletleriniz olmadığı sürece kaynamış suyu içmekten kaçınmaksa, diğerlerine anlatmak için kampa geri dönmeniz ve ardından paketleme ve yürüyüş sürecini başlatmanız gerekir. Bu nedenle ilk arkadaşınızın toplanıp gitme tavsiyesine uymak çok daha kolay olurdu. 
Peki ne yapmaya karar veriyorsun? Diyelim ki daha fazla tavsiye aramamaya karar verdiniz ve suyu kaynatıp soğuduğunda içmenizi tavsiye ediyorsunuz. Şimdi kararınızın arkasındaki nedenleri arkadaşlarınıza vermeye borçlusunuz. İlk sebebiniz, ikinci arkadaşınızın akarsuyun zehirli olması durumunda içindeki her şeyin ölü görüneceğine dair sözünü dikkate almamanızdır. Ölümcül şeyler canlı olabilir ve sağlıklı görünebilir. İkinci sebebiniz, bekçi istasyonundaki o tabelayı tekrar gözden geçirmenizdir. Giardia'yı öldürmek için hiçbir şey işe yaramazsa, o zaman parka girmenize izin verilmez ya da şahsen uyarılırdınız. Tabelada istasyonda sterilizasyon tabletlerinin bulunmadığı belirtilmekte ve bu da suyun sterilize edilmesinin onu güvenli hale getireceğini ima etmektedir. Bu durum ne kadar güvenli olabilir? Sterilizasyon, tüm canlı organizmaları öldürmek veya uzaklaştırmak anlamına gelir, ancak tüm zararlı kimyasalları değil. Benzin içeren suyu sterilize etseydin, bu içmeyi güvenli yapmazdı. Yani sorun kesinlikle mikroorganizmalardır. Artık korucular, yürüyüşçülerin suyu kaynatıp sterilize etme eğiliminde oldukların kesinlikle biliyorlar. Kaynatma işe yaramazsa, tabelada öyle olacağını düşünüyorsunuz. O zaman Afrika'daki insanlara kolerayı önlemek için içme suyunu kaynatmaları söylendiğini duyduğunuzu belli belirsiz hatırlıyorsunuz ve koleraya bir parazit, bakteri veya suda yaşayan bir şey olduğunu düşünüyorsunuz. Kolera Giardia'dan çok farklı olabilir mi merak ediyorsunuz. Bütün bunları düşündügünüzde, kaynamanın işe yarayacağı sonucuna varıyorsunuz. Dolayısıyla, ilk arkadaşının Giardia gibi kötü bir hastalığa yakalanma tehlikesi konusundaki endişesi, hastalığa yakalanma olasilığının düşük olmasıyla fazlasıyla telafi ediliyor.

Kararın böyle verdin diye düşünelim. Bu durum mantıklı mı? Evet, çünkü çok nitelikli muhakemeye dayalıdır. Bu, sizin yerinize bir uzmanın vereceği en iyi karar mı? Bunu bilmiyorsunuz, ancak evet, uzmanlar, bir veya iki dakika kaynatırsanız dere suyunun güvenli olacağını söylüyor. Giardia'ya yüksek sıcaklıkta uzun süre yaşayamayan protozoa neden olur. Diğer mikroorganizmalar bu ısınmadan sağ çıkabilir, ancak genellikle herhangi bir insan hastalığına neden olmazlar. İnsanların su arıtma tabletlerini kullanmasının nedeni, kolaylık sağlamak içindir. Tabletlerin kullanılması, suyun kaynaması ve ardından içme sıcaklığına kadar soğuması için ekstra zamanın olmasını önler (Dowden, 2019). 
Şimdi örnek olayda kullanılan mantıksal akıl yürütme ilkelerine dönelim. Hepimiz bu ilkeleri her gün kullanıyoruz, bu nedenle bu tartışma zaten bildiklerinizi hatırlatmaktan başka bir şey değil. Bir ilke, yeterince iyi nedenleriniz yoksa bir sonucu kabul etmeden önce nedenleri sormaktır. Benzer şekilde, insanlardan kendi sonucunuzu kabul etmelerini bekliyorsanız, onlara takdir edebilecekleri nedenler sunmak sizin sorumluluğunuzdur. Bu sözü inceleyelim. Herhangi bir sirayla bir veya daha fazla sebeple desteklenen bir sonuca, muhakemeci tartışma olmasa bile kanıt denir. Mantıklı olmak, başkalarının kabul etmesini bekliyorsanız, sonucunuzu desteklemek için bir kanit vermeniz gerektiği anlamına gelir. İnsanlara anlayabilecekleri nedenlerle tartışmalar ortaya koyun, aşırı teknik terimlerle tartı̧maya girmeyin. Aksi takdirde, anlamsız konuşuyor olabilirsiniz. Nedenlerinizi hedef kitlenize göre uyarlayın. Bir kanıt sunarken amacınız, nedenlerinizi izleyicilerinizin görmesi için tasarlamak olmalıdır. İnsanlardan kendi sonucunuzu kabul etmelerini bekliyorsanı, onlara takdir edebilecekleri nedenler sunmak sizin sorumluluğunuzdur. Bunu söylemenin bir başka yolu da, dinleyicilerinizin sonucun onu desteklemek için verilen nedenlerden kaynaklandığını görmesi gerektiğidir (Toulmin, 1958).

Mantıksal akıl yürütme ilkelerine devam edildiğinde örneğin, kamp gezisi hikayesinde, hem ilk arkadaşınızın söylediklerine hem de ikinci arkadaşınızın söylediklerine dikkat ettiniz ve Giardia hakkında soru soracak bir park bekçisi olmasını dilediniz. Uyguladığınız temel ilke, daha alakalı bilgilere sahip olmanın değerini kabul etmektir. Kamp durumunda, toplanip eve gitmeyi seçmek mantıksız olmazdı, ama muhtemelen en iyi karar da olmazdı. Önemli olan, ilgili kanıtları değerlendirmeye yönelik ciddi bir girişim temelinde kararınızı vermektir. Bunu, gitmenin veya kalmanın artılarını ve eksilerini tartarak olasılıklara ve sonuçlara dikkat ettiğinizde yapabilirsiniz. $\mathrm{Bu}$ artı ve eksi yanları değerlendirilirken aşağıdaki olasılıklar ele alınabilir:

- Olası hareket tarzlarını göz önünde bulundurmak (toplanıp dişarı çıkmak, suda kalmak ve suyu kaynatmak, su elde etmek için bir dut ağacı veya islak bir yaprak aramak),

- Çeşitli eylemlerin sonuçlarını tahmin etmek (susamak, kamp gezisine devam etmek, hastalığa yakalanmak),

- Bu sonuçları değerlendirmek (susamak olumsuzdur, kamp gezisine devam etmek olumludur, Giardia'dan hastalık kapmak korkunç olur), 
- Bu çeşitli sonuçların gerçekten ortaya çıkma olasılıklarını göz önünde bulundurmak (dereden içtikten sonra susamamanız yüzde yüz olasıdır, ancak içerseniz bir hastalığa yakalanmanız çok az olasıdır).

Neye inanacakları ya da ne yapacakları sorusuyla karşı karşıya kalan mantıksal akıl yürütenler, zamanları varsa artıları ve eksileri tartmaya çalışırlar; Olumsuz herhangi bir şeyi bilerek saklarken, kendi çıkarımlarını destekleyen nedenler için etrafta arama yaparlar. Yani, konu hakkında belirli bir pozisyon almanın nedenlerini belirlerler ve bu pozisyonu almalarına karşı olan nedenleri tespit ederler; sonra iki neden kümesini tartarlar ve adil bir şekilde bir sonuca varırlar.

Eleştirel düşünmelerde, her zaman artıları ve eksileri tartma yöntemi kullanılmaz. Artıları ve eksileri tartmak, yalnızca potansiyel eylemlerinizin önemli sonuçlarının bilindiği ve bu sonuçları değerlendirmek için yeterli zamanın olduğu sınırlı durumlarda kişiye iyi bir yanıt verir. Çoğu durumda, en iyi düşünce, kısa yollar kullanmayı gerektirir. Örneğin; hızlı tahminler yapmak veya güvenilir bir arkadaşınızın sizin adınıza karar vermesine güvenmek gibi (Akar, 2007). Eleştirel düşünmek, kişinin kendi güçlü kanıtlarını oluşturmasında yardımcı olacaktır. Bu da değerlendirilen kanıtlara dayanarak ileri sürülen tüm iddiaları sunabilmek ve gerekçelendirebilmek anlamına gelir. Eleştirel düşünme, çeşitli problemleri çözmede ve bu problemlere daha mantıklı kanıt geliştirmeye olanak sağlayan bir düşünmedir. Kişinin kendi akanıtve fikirlerini haklı çkarmak için kanıtları kullanabilecek ve bunlardan yararlanabilecek formu oluşturması adına eleştirel düşünme mantıksal düşünmeden yararlanır (Postigo, Hardy, ve Foster, 2015).

Aynı şekilde biraz kömür gördünüz diyelim. Bu bir UFO inişinin iyi bir kanıtı değildir. Benzer şekilde, size "dün öğleden sonra markette arkadaşım 'A' ile tanıştım" denilse, bunun böyle olduğuna dair çok az kanıt istenir. Ancak, size şu söylense, "son on yıldır ölmüş olan arkadaşım 'A' ile dün öğleden sonra markette tanıştım" muhtemelen yalan söylendiği düşünülür. Söylenilenleri doğru olarak kabul etmeden önce kesinlikle iyi kanıtlar istenir. Bu durumda ortak arkadaşların onayı bile yeterli delil olmayacaktır. Ancak bunun yerine şöyle denilebilir. Dün öğleden sonra markette arkadaşım ' $A$ ' ile tanıştım. Tahta bir ayağı var ve dün çiftler tenis maçında iki set kazanmış. $\mathrm{O}, \mathrm{Av}-$ rupa tenis takımının en iyi oyuncusudur. Bu ifade, onun on yıldır ölmüş olması ifadesi kadar tuhaf değildir. Eğer bu cümle doğruysa, insanları bu ger- 
çeğe ikna etmek daha kolay olacaktır. Mantıksal akıl yürütme ilkelerine güvenmemekle, bazı insanlar, Ay'da antika uçakların olduğuna, UFO'ların birinin arka bahçesine indiğine ve ölü arkadaşların hayata döndüğüne çok kolay inanma hatasına düşebilir. Bütün bunlar olmuş olabilir, ancak şu anda mevcut olan kanitlar son derece zayıf durumdadır. Bunlara inanmanin tek nedeni, birkaç kişinin bunların gerçekleştiğini söylemesidir. Ve bunların muhtemelen gerçekleşmediğini düşündüren birçok arka plan inancı ve sağduyu bulunmaktadır. Nedenlere olan güvenin derecesi, bu nedenlerden çıkarılan sonuca verilen güven derecesini doğrudan etkiliyorsa, bu mantıklı olmanın bir işaretidir (Booth, Colomb \& Williams, 1995).

Mantıksal akıl yürütme kurallarına uymak bazı insanlara diğerlerinden daha kolay gelir. Fakat mantıklı olmak, yüksek nitelikli kararlar almanın tek yolu değildir. Bazen bu kararlar kazara alınır; bazen bir yıldız falına uymak gibi mantıksız yollarla yapılabilir. Mantıksal akıl yürütme genelde işe yarayan bir yön taşır. Örneğin; uzman, "O şeyi içme; seni öldürebilir" dediğinde, bu durum kişiye mantıklı ve akılcı gelecektir. Bu nedenle de kişi içmeyi bırakacaktır. Fakat mantıklı düşünemeyen kişi, "Geçmişte uzmanlar yanıldı; ben yine de içiyorum" diye düşünecektir. Herkes en iyi kararların gerçeklere dayandığını bilir, ancak gerçeklerin kişiye söylenen şeylerden nasıl ayırt edilebileceği konusu önemlidir. Bu noktada tutarsızlıkları kabul etmekten kaçınmak gerekir. Çünkü mantıklı ve akılı kararlar almak, tutarlı olmaya bağlıdır (Doğanay \& Ünal, 2006). Örnek olayda ele alınan konuda bir arkadaşınızın kamp gezisini sonlandırma tavsiyesinin, diğer arkadaşınızın devam etme tavsiyesiyle tutarsız olduğunu fark edildiği anda bu mantıksal akıl yürütme ilkesinden yararlanılmış olmaktadır. Bir tutarsızlığı tespit etmek, hatanın nerede olduğunu ortaya çıkarmaz, ancak bir hatanın mevcut olduğunu söyler. Birisi Neptün'ün yüzeyinin sifırın altında ortalama 200 dereceden daha soğuk olduğunu söylüyorsa ve kız kardeşi neredeyse o kadar soğuk olmadığını söylüyorsa, ikisinden biri gerçekler hakkında yanılıyor olması gerekir. Neptün hakkındaki gerçekler bilinmese bile bu durum ayırt edilebilir. Dolayısıyla mantıksal muhakemenin temel ilkelerinden biri şudur: Kendi muhakemenizde tutarlı olun ve başkalarının muhakemesinde tutarsızlığa dikkat edin. Sadece anlam olarak hepsinin doğru olamayacağını anlarsanız, ifadeler mantıksal olarak birbirleriyle tutarsız olur. Mantıksal olarak tutarsız değilse, bir grup ifade mantıksal olarak tutarlıdır. Bir ifade genellikle bildirim cümlesiyle 
yapıldığından, birbirleriyle tutarlı veya tutarsız cümlelerden bahsedilir (Toulmin, 1958).

Bu noktaya kadar, karar gerektiren durumlarda mantıksal olarak akıl yürütmenin önemi ele alınmıştır. Burada ya ne yapılacağına ya da neye inanılacağına dair bir karar oluşmuştur. Yol boyunca, iyi bir muhakeme, yani yüksek nitelikte muhakeme için çeşitli temel kurallar verilmiştir. Peki gündelik hayatta mantık hangi durumlarla değerlendirilebilir?

\section{Gündelik Mantık: Kanıt, İnançlar ve Doğru Düşünme}

Her zaman, her yerde ve herhangi birinin yetersiz delil üzerine herhangi bir şeye inanması yanlıştır. (Clifford, 1879, s.186). İngiliz filozof ve matematikçi W. K. Clifford'un iddiası kişi yeterli kanıta sahip değilse herhangi bir şeye inanmak da etik değildir. Birçoğu, Clifford'un iddiasının çok güçlü olduğunu ve gerekli kanıtlara sahip olunmayan şeylere inanmanın kabul edilebilir olduğunu savunmaktadır. Clifford ile kesinlikle ayn fikirde olsun ya da olmasın, iyi bir noktayı ortaya koyduğu aşikârdır. Her gün milyonlarca insan yetersiz kanıta dayalı kararlar vermektedir. Bu iddiaları gerekçelendirmek için gerekli zamanı, çabayı ve araştırmayı harcamadan bir takım şeylerin doğru veya yanlış olduğunu iddia edenler bulunmaktadır. İnsanların, üzülmeye başlayana kadar aynı iddialarda bulunmaya devam ettikleri veya tartışmaya yeni bir şey eklemeden sadece konumlarını yeniden ifade etmeye devam ettikleri bir tartışmalar olmaktadır. Bu durumlar genellikle, "Pekala, sanırım sadece katılmayacağımızı kabul edeceğiz" veya "Senin fikrini alma hakkın var ve benim hakkım var ve biz onu öylece bırakmak zorunda kalacağız. "bu noktada insanlar kendisine şu soruyu sormalıdır. "İnsanlar gerçekten istedikleri herhangi bir fikre sahip olabilir mi?" Eleştirel düşünme bakış açısından, cevap hayırdır. İnsanlar yasal olarak inançlarına ve fikirlerine hak kazanmış olsalar da, mantıksal akıl yürütme ve kantlarla desteklenmeyen bir fikre hak kazandıklarını hissetmeleri entelektüel açıdan sorumsuz olacaktır. Bu iddiada bulunan insanlar, ifade özgürlüğünü düşünce özgürlüğüyle birleştirmektedir. Basit bir örnek bu noktayı açklayacaktır. Birinin Ay'ın yeşil peynirden oluştuğuna inandığını varsayalım. Ay'ın yeşil peynirden yapıldığına dair inancına yasal olarak hakkı olsa da, bu inanca rasyonel olarak hakkı yoktur, çünkü inanmak için birçok neden ve Ay'ın yeşil peynirden oluşma- 
dığını gösteren çok sayıda kanıt vardır. İyi düşünürler sürekli olarak inançlarını sorgular ve inançlarının doğru olduğundan emin olmak için birçok kanıt kaynağını inceler. Elbette, insanlar genellikle garanti edilmiş gibi görünen ancak daha sonra doğru olmadığı anlaşılan, örneğin dünyanın düz olduğu, bebek beşiklerini kurşun boyayla boyamanın kabul edilebilir olduğu gibi inançlara sahiptir. Bununla birlikte, iyi bir düşünür, bu görüşlerin yanlış olduğu kanıtlandığında görüşlerini değiştirmeye istekli olan kişidir. Birisinin bir konu hakkında belirli bir görüşe veya pozisyona hakkı olduğunu iddia etmek için yerine getirilmesi gereken belirli kriterler vardır. Ayrımın çok net olmadığı başka örnekler de var. Örneğin, bazı insanlar kadınların erkeklere boyun eğmesi gerektiğine inanır. Bu inancı pek çok nedenden dolayı savunurlar, ancak baskın olan, belirli dinlerin durumun böyle olduğunu iddia etmesidir. Dini bir metnin kadınların erkeklere hizmet etmesi gerektiğini iddia etmesi, bu iddiaya inanmak için yeterli kanıt sağlıyor mu? Birçok insan bunun olmadığına inanmaktadır. Ancak, dini metinlerini bu şekilde yorumlayan birçok kişi, bu metinlerin bu tür iddialar için yeterli kanıt sağladığını iddia edecektir (Postigo, Hardy, \& Foster, 2015).

Neyin yeterli kanıtı oluşturduğuna dair zor ve hızlı tanımlamalar yapmanın tehlikesini ve zorluğu burada görülmektedir. Kitaplardaki yazılı kelimelerin doğrudan ilahi kaynaklardan geldiğine inanılırsa, bu kelimelere kanitlarının gücü açısından en yüksek güvenilirliği vermeye eğilimli olunur. Bununla birlikte, yazılı kelimeler yazarları tarafindan sunulan kanitlar olarak görülürse, o zaman metin, sunulan kanıta ve mantığa dayanarak analiz edilir. İkinci durumda, bu insanların yanlış olduğunu ve sadece kültürel olarak erkek egemen çevrelerine dayanarak iddialarda bulundukları görülür.

Tabii ki, tüm insanlar istediklerine inanma özgürlüğüne sahiptir. Ancak, hak sahibi olmak bir gerekçe olarak düşünülürse, o zaman tüm insanların kendi görüş ve inançlarına hakkı olduğunu söylenemez. Bu noktada neye neden inanıldığını düşünmek gerekir. Eğer inancınız yoksa fikirleriniz için nedenler veya destekleyici kanıtlar, bulmaya çalışmalısınız. Kanıt olmadan tartışmalara kapılmamalıdır. En önemlisi, iyi bir düşünür olarak, çeşitli konumların, özellikle de kendi sorunlarınızdaki güçlü ve zayıf yönlerini kabul etmeye istekli ve muktedir olmak gerekir. Aynı zamanda, kanıt arayışında karşı konumun daha güçlü olduğu fark edildiğinde, kendi konumunuzu değiştirmeye istekli olunmalıdır. Başkalarının kanıtları veya mantıksal akıl yürütme ile desteklenmediğinden şüphelenildiği takdirde yargılamayı askıya 
almak da doğru düşüncenin bir işareti olacaktır. Yargılamayı askıya almak kişiyi hatalardan ve olumsuz sonuçlara yol açan aceleci kararlar almaktan koruyabilir.

\section{Sonuç}

Mantıksal akıl yürütme, iyi kararlar almak ve gerçeği yalandan ayırmak için bir rehberdir. Bu çalışmada birkaç mantıksal akıl yürütme vakası incelenmeye çalışılmıştır. Ayrıca muhakemede bazı yaygın hatalara da işaret edilmiştir. Ele alınan örnek olaydan ve örneklerden mantıksal akıl yürütmenin aşağıdaki ilkeleri çıkarılabilir:

Bir sonucu kabul etmeden önce nedenler istemek, sonucunuzu desteklemek için bir kanıt sunmak, hedef kitleye nedenleri belirlemek, tasarım sonucu ima etmek için nedenleri ele almak, daha alakalı bilgilere sahip olmanın değerini kabul etmek, bir durumun artıları ve eksilerini tartmak, olası eylem yollarını değerlendirmek, çeşitli yolların sonuçlarına bakmak ve sonuçları değerlendirmek, bu çeşitli sonuçların gerçekte ortaya çıkma olasılıklarını irdelemek, önemli kararlar verme konusunda acele etmemek, durumun ışığında söylenenleri değerlendirmek, arka plan bilginizi ve sağduyunuzu kullanarak sonuçlara varabilmek, olağanüstü ifadelerin olağanüstü derecede iyi kanıt gerektirdiğini unutmamak, uzmana danışmak, neden sonuç ilişkisini göz ardı etmemek, kendi muhakemenizde tutarlı olmak, kendinizin ve başkalarının muhakemelerinde tutarsızlık olabileceğini düşünerek hareket etmek, açıklamaların tüm ilgili gerçeklere uyup uymadığını kontrol etmek, alınan karar doğru ise alternatif açılamalar olduğunu göstererek rakibinizin açıklamasını daha az inandırıcı yapabilmek, konuya sadık kalmak ve yeterli kanit elde edene kadar bir sonuç çıkarmamaktır.

Bunun yanında eleştirel bakış ile mantıksal muhakemede bulunmak veya mantıksal düşünmeyi gerçekleştirmeye çalışmak da gerekir. Çünkü eleştirel düşünmek, fikirleri incelemek, onları bilgiye göre değerlendirmek ve değerleri hakkında kararlar vermektir. Eleştirel düşünmenin amacı, "nesnel" bir konumu korumaya çalışmaktır. Eleştirel düşünüldüğünde, bir tartışmanın tüm yönlerini tartar ve güçlü ve zayıf yönleri değerlendirilir. Dolayısıyla, eleştirel düşünme becerileri, iddiaları desteklemek için kullanılan kanıtın sağlamlığını test eden iddiaların sağlamlığını test eden bir kanıtın tüm yönlerini aktif 
olarak araştırmaktır. Eleştirel düşünürken amaç, okuduğunuza veya düşündüğünüz şeye nesnel bir şekilde yanıt vermektir. Bu noktada açık fikirli olmak ve yazarın iddialarını sorgulamaya hazır olmak gerekir. Bununun nasıl yapılacağı konusu ile ilgili sorular ne okunulduğu ve neden okunulduğuna bağlı olarak değişecektir. Sonuç olarak eleştirel düşünme, bir okuyucu olarak okuduğunuz şeydeki kanıtları değerlendirmeye ve sahte veya mantıksız akıl yürütmeyi tanımlamanıza olanak tanıyacaktır. Bu nedenle de mantıksal akıl yürütme ile eleştirel bakış açısı birbiri ile paralel olan düşünme tarzını ele vermektedir. 


\title{
EXTENDED ABSTRACT
}

\section{Logical and Critical Perspective on Case Study}

\author{
Dilek Başerer \\ Atatürk University
}

The aim of this study is to reveal these skills with a critical perspective while developing logical reasoning skills. Logical reasoning skills are effective in understanding someone's opinion, generating reasons for goals, evaluating reasons given by others, deciding what to do and not to do, and deciding what information to accept or reject. Critical thinking skill is the ability to make judgments. It is therefore linked to logical thinking.

Qualified reasoning can be called logical reasoning or critical thinking. Logical reasoning is a skill that can be learned and developed. The opposite of logical reasoning is uncritical thinking. For this reason, in parallel with logical reasoning, critical perspective is also included in the study. The purpose of this study is to explain what it means to be logical, reasoning logically, and touch upon its relationship with critical thinking through case studies and examples. The study also demonstrates the usefulness of logical reasoning as a way of making more effective decisions about one's own life, and offers insight into making critical decisions about what to believe and do. The study is important in terms of seeing the inconsistency in sentences, detecting and preventing clarity, deficiency, problems, errors in the statements (reasoning errors) and producing and developing explanations with evidence.

Since it is a study about showing and interpreting how to look at an event logically and critically based on case studies, the method was created with a literature review. Literature review is defined as the systematic search, screening and interpretation of research results and theoretical literature published on a particular subject (Cooper, 1989; Bruce, 1994; Caspers, 1998; Afolabi, 1992).

The data collection tools of the study are composed of articles and books on logical thinking and critical thinking in the literature.

In this study, the literature review was carried out in four stages: search, scanning, compilation and interpretation. 
Search Process: In this process, articles and books were researched on logical thinking and critical thinking in order to search the literature.

Screening Process: The articles and books found suitable for the purpose of the study were scanned by creating a scanning frame.

Compilation Process: At this stage, the themes were reached with the notes taken. The themes that emerged from the review of the articles were collected and named under the following headings: logic, logical thinking, reasoning, logical reasoning, critical thinking.

Interpretation Process: After the screening process was completed, the case study was interpreted within the framework of the themes discussed.

Imagine this situation. You are on a four-day backpacking ride through a national wildlife park with two friends. The summer weather is great, the scenery is exotic and you are having a good time. You drove a few hours to get to the area and then walked six hours to your current camp site. The three of you carried all your food, water, sleeping bags and tents. Last night, you discovered that someone accidentally broke the large water bowl. For this reason, there is no water with you. Although there is a stream nearby, you normally don't drink from a stream, and you remembered that your water sterilization tablet packs were in the pocket of your other jacket you left at home at the last minute. Three of you are thirsty and you only have dehydrated food with you, except for four apples. What would you do in this situation?

Logical reasoning is a guide to making good decisions and to distinguish truth from lies. In this study, several logical reasoning cases have been tried to be examined. It has also pointed out some common mistakes in reasoning. The following principles of logical reasoning can be deduced from the case and examples discussed:

Asking for reasons before accepting a result, providing evidence to support your conclusion, identifying reasons to the target audience, addressing reasons to imply a design result, recognizing the value of having more relevant information, weighing the pros and cons of a situation to evaluate possible paths of action, to look at the results of various paths and to evaluate the results, to examine the likelihood of these various consequences in reality, not to rush to make important decisions, to evaluate what is said in the light of the situation, to draw conclusions using your background knowledge and common sense, extraordinary expressions Remembering that it requires 
good evidence, consulting an expert, not ignoring cause and effect relationship, being consistent in your own judgment, acting in the mind that there may be inconsistency in your own and others' reasoning, checking whether the explanations fit all relevant facts.

\section{Kaynakça / References}

Afolabi, M. (1992). The review of related literature in research. International Journal of Information and Library Research, 4(1), 59-66.

Akar, C. (2007), Ilköğretim öğrencilerinde eleştirel düşünme becerileri. Yayınlanmamış Doktora Tezi, Gazi Üniversitesi Eğitim Bilimleri Enstitüsü, Ankara.

Başerer, D. (2017). Bir düşünme türü olarak mantiksal düşünme. Akademik Sosyal Araştırmalar Dergisi, 5(41), 433-442.

Booth, W., Colomb, G.G., Williams, J.M. (1995) Making good arguments: an overview. in The Craft of Research, London: The University of Chicago Press.

Bozdoğan, A. (2007). Fen Bilgisi çalişma yapraklari ile öğretimin öğrencilerin fen bilgisi tutumuna ve mantiksal düşünme becerilerine etkisi. Yayınlanmamış Yüksek lisans Tezi. Çukurova Üniversitesi, Adana.

Bruce, C. S. (1994). Research student's early experiences of the dissertation literature review. Studies in Higher Education, 19(2), 217-229.

Caspers, J. S (1998). Hands-on instruction across the miles: using a web tuturial to teach the literature review research process. Research Strategies, 16(3), 187-197.

Clifford, W. K. (1879) The Ethıcs Of Behef. In L. Stephen \& F. Pollock (Eds.), Lectures and Essays (Cambridge Library Collection - Philosophy, p. 177-211). Cambridge: Cambridge University Press. doi:10.1017/CBO9781139149884.007

Cooper, H. M. (1989). Integrating research: A guide for literature reviews, (2nd ed.), Newbury Park, Calif: Sage Publications.

Cüceloğlu, D. (2003), İyi düşün doğru karar ver. İstanbul: Sistem.

Çıbık, A. S. (2006). Proje tabanlı öğrenme yaklaşımının fen bilgisi dersinde öğrencilerin mantıksal düşünme becerilerine ve tutumlarna etkisi. Yayınlanmamış Yüksek lisans Tezi). Çukurova Üniversitesi, Adana.

Demirel, Ö. (2005). Öğretme Sanatı. (8. Baskı). Ankara: Pegem A.

Doğanay, A. ve Ünal F. (2006). Eleştirel düşünmenin öğretimi. A. Şimşek (Ed). Içcrik Türlerine Dayalı Öğretim. Ankara: Nobel.

Dowden, B. (2019). Logical Reasoning. USA: Wadsworth Publishing.

Kazanc, O. (1989). Egitimde Elestirici Düsünme ve Ögretimi. Ankara: Kazana Hukuk. Koç, C.(2011), aktif öğrenmenin okuduğunu anlama ve eleştirel düşünme üzerindeki etkileri, Cumhuriyet Üniversitesi Sosyal Bilimler Dergisi, 35(1), 28-37. 
Korkmaz Baylav, H. (2002). Fen eğitiminde proje tabanlı öğrenmenin yaratıcı düşünme, problem çözme ve akademik risk alma düzeylerine etkisi. Yayınlanmamış Yüksek lisans Tezi). Hacettepe Üniversitesi, Ankara

Postigo G., Hardy, J. ve Foster, C. (2015). With good reason: A guide to critical thinking. Bridgepoint Education,

Şahinel, S. (2007). Eleştirel düşünme. Ankara: Pegem A.

Semerci, Ç. (2003). Elestirel düsünme becerilerinin gelistirilmesi. Egitim ve Bilim Dergisi, 27(127), 64-70.

Toulmin, S. (1958). The uses of argument. Cambridge: Cambridge University Press,

Zayif, K. (2008). Öğretmen adaylarının eleştirel düşünme eğilimleri. (Yayınlanmamış Yüksek Lisans Tezi), Sosyal Bilimler Enstitüsü, Bolu.

\section{Kaynakça Bilgisi / Citation Information}

Başerer, D. (2021). Örnek olay üzerinden mantıksal ve eleştirel bakış açısı OPUS-Uluslararası Toplum Araştırmaları Dergisi, 17(37), 4702-4720. DOI: $10.26466 /$ opus.872707 